\title{
Correction to: Development of ship weather routing system with higher accuracy using SPSS and an improved genetic algorithm
}

\author{
Chong Pan ${ }^{1} \cdot$ Zhanshuo Zhang $^{1} \cdot$ Weikang Sun ${ }^{2} \cdot$ Jun Shi $^{2} \cdot$ Hongbo Wang $^{1}(\mathbb{C}$
}

Published online: 24 March 2021

(c) The Japan Society of Naval Architects and Ocean Engineers (JASNAOE) 2021

Correction to: Journal of Marine Science and Technology https://doi.org/10.1007/s00773-021-00800-6

The author would like to update the references 1, 3, 4 and 23.

The updated references are available in this correction.

1. Li P (2019) Research and simulation of multi objective ship weather route optimization algorithm [D]. Jilin University, Jilin

3. Zhang Z, Liu T, Cao Y et al. (2020) Overview and development situation of marine weather routing service for ships [J]. J Mar Meteorol 40(3):11-16

4. Zis TPV, Harilaos NP, Li D (2020) Ship weather routing: a taxonomy and survey [J]. Ocean Eng 213:107697
23. Singh V (2018) Fuel consumption minimization of transport aircraft using real coded genetic algorithm [J]. Proc Inst Mech Eng Part G J Aerosp Eng 232(10):1925-1943

Publisher's Note Springer Nature remains neutral with regard to jurisdictional claims in published maps and institutional affiliations.

The original article can be found online at https://doi.org/10.1007/ s00773-021-00800-6.

Hongbo Wang

wang_hongbo@jlu.edu.cn

1 State Key Laboratory on Integrated Optoelectronics, College of Electronic Science and Engineering, Jilin University,

Changchun 130012, China

2 CSSC Marine Technology Co., Ltd, Shanghai, China 